\title{
Mapeando o Pouso Frio: dinâmicas de construção de um bairro na cidade de Toledo/PR
}

Mapping the Pouso Frio: construction dynamics of a neighborhood in the city of Toledo/PR

\author{
Maria Cristina de Castro Pereira*
}

\section{Resumo}

Este artigo descreve e problematiza o processo histórico de constituição de um bairro - o Pouso Frio - na cidade de Toledo, Oeste do Paraná, a partir da década de 1940. Inicialmente uma área de ocupação, esse espaço foi construído por diferentes sujeitos, em sua maioria, vindos do Norte do Paraná, São Paulo, Minas Gerais e Paraguai, ocultados na História Oficial elaborada para o município. Nas primeiras décadas em que viveram no bairro, enfrentaram o medo sempre presente de perder seus parcos investimentos em terrenos sem escrituração. Ainda conviveram, por exemplo, com a ausência de energia elétrica, da água encanada, do transporte público e da rede de esgoto. Os diálogos estabelecidos com moradores do Pouso Frio permitiram delinear um conjunto de trajetórias e expectativas que os aproximaram e os uniram na luta por melhores condições de moradia e acesso à cidade.

Palavras-chave: Moradia; Ocupação; Trabalhadores; Pouso Frio.

\begin{abstract}
This article describes and discusses the historical process of formation of a neighborhood - Pouso Frio in the city of Toledo, west of Paraná, from the 1940s Initially an occupation area, this space was built by different subjects in their mostly from the north of Paraná, São Paulo, Minas Gerais and Paraguay, hidden in the Official History prepared for the city. In the first decades they lived in the neighborhood faced the ever-present fear of losing their meager investments in land without bookkeeping. Still they lived with the absence of electricity, tap water, public transport and sewage system, for example. The dialogue established with residents of Pouso Frio allowed outlining a set of trajectories and expectations that came and joined them in the fight for better living conditions and access to the city.
\end{abstract}

Keywords: Home; Occupation; Workers; Pouso Frio.

Pesquisadores e gestores públicos têm sido omissos em relação à presença e atuação de milhares de trabalhadores pobres no processo histórico de construção da cidade de Toledo, na região Oeste do Paraná ${ }^{1}$. Tais trabalhadores veem de diversas regiões do Brasil e do Paraguai em busca de melhores condições de vida e trabalho que,

\footnotetext{
* Doutoranda do Programa de Pós-graduação em História pela Universidade Estadual do Oeste do Paraná (UNIOESTE). Professora do Instituto Federal do Paraná (IFPR).

Recebido em outubro de 2016 | Aprovado em fevereiro de 2017.

${ }^{1}$ O Município de Toledo está situado na Região Oeste do Paraná. Sua população atual é de 130.295 habitantes, conforme estimativa do IBGE. A Região Oeste do Paraná está dividida em microrregiões: a de Toledo, Cascavel e Foz do Iguaçu. Toledo possui um território de $1.205,501 \mathrm{~km}^{2}$, sendo a parte urbana possuidora de uma área de $54,56 \mathrm{~km}^{2}$, com 22 bairros.
} 
em grande número, ocuparam esta ampla área da cidade, chamada de Pouso Frio. O primeiro nome do bairro deve-se ao fato de ter sido, por muito tempo, uma parada de descanso para homens e animais que transportavam erva-mate até a Argentina. A essa primeira condição de pouso somou-se o fato de que a partir do final da década de 1940 a região começou a ser ocupada por trabalhadores que não dispunham de escrituração dos terrenos e nem mesmo sabiam de quem era a área. Portanto, "Pouso Frio".

Em um texto publicado no jornal Nova Geração ${ }^{2}$, as condições de vida e moradia encontradas no Pouso Frio são apontadas pelos próprios moradores entrevistados pela equipe do jornal: fundos de terrenos mal divididos, comportando até quatro "ranchinhos" de pequeno porte; falta de iluminação pública (gerando gastos com querosene e gás, além de impossibilitar o funcionamento de comércios que necessitavam de energia elétrica na região, obrigando os moradores a se deslocarem até o centro da cidade); medo de reformar ou ampliar casas e perder o investimento (os moradores temiam perder suas casas, já que desconheciam os proprietários legais das terras); entre outras dificuldades.

Em meados do século XX, não só no Oeste paranaense, mas em todo o Brasil, foram experimentadas intensas movimentações territoriais de trabalhadores. A população brasileira, antes predominantemente rural, experimentou um rápido

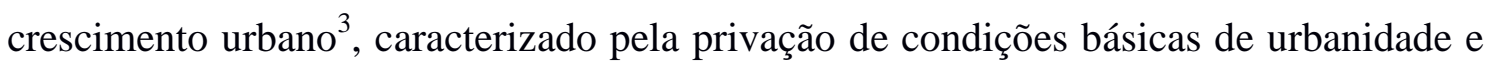
inserção efetiva na cidade de boa parte da população. Outra característica marcante das crescentes cidades brasileiras foi - e ainda é - a ilegalidade, ou seja, a construção desses espaços é marcada pela presença de ocupações, favelas e outros loteamentos ditos

\footnotetext{
${ }^{2}$ O Jornal Nova Geração foi uma fusão de outros dois jornais da cidade, o Tribuna do Comércio e $\mathbf{O}$ Atecano. O primeiro jornal era produzido pela ACIT (Associação Comercial e Empresarial de Toledo), enquanto o segundo pela ATEC (Associação Toledana dos Estudantes em Curitiba). Ambos tinham circulação mensal. Nova Geração circulou mensalmente entre os anos de 1973 e 1978, e tinha como redator chefe Oscar Silva e Nelton Friedrich como diretor proprietário, ambos com vínculo com a antiga Tribuna do Comércio. Em 1977, constava como diretor geral Edílio Ferreira. Esee jornal possui dois momentos: um primeiro em que a pauta era composta por muitas matérias locais e regionais, com a particularidade de haver grande interesse nas relações dessas dimensões (quais dimensões? Não localizei o referente) com o governo estadual e o segundo, verificado em 1978, quando o jornal apresentava uma pauta diferenciada e, no editorial de 5 de setembro daquele ano, foram apontadas questões que orientariam seu perfil, após ficar um tempo fora de circulação. Nesse momento, o veículo de informação engajou-se no processo de abertura política do regime militar e efetuava críticas à ditadura, além de dar visibilidade ao MDB e à lutas, como a "anistia". Sem abandonar por completo as notícias locais e regionais, a pauta desse jornal passou a ser composta por matérias sobre o Brasil e a América Latina e, dessa maneira, conferia-lhes amplo destaque (LANGARO, 2012, p. 62).

${ }^{3} \mathrm{O}$ contingente populacional rural em 1950 era de 33.161.506 habitantes, enquanto a população urbana era de 18.782.891 habitantes. Em 1960 esse número cresce para 31.303.034 habitantes, com a população rural mantendo-se em torno de 38.767.423 habitantes. A inversão populacional ficou mais evidente na década de 1970: 41.054.053 habitantes no campo e 52.084.984 habitantes nas cidades (SANDOVAL, 2014).
} 
“irregulares”. A arquiteta e urbanista Raquel Rolnik $\left(2006^{4}\right)$ aponta que essas ocupações estão presentes em quase $100 \%$ das cidades com mais de 500 mil habitantes e em $80 \%$ das cidades entre 100 mil e 500 mil habitantes. Até mesmo nos municípios com menos de 20 mil habitantes esses loteamentos aparecem em mais de $30 \%$ dos casos.

A área de ocupação chamada Pouso Frio na cidade de Toledo/PR, nas décadas de 1970-90, foi palco de conflitos e movimentações que, entre outras implicações, provocou a remoção de dezenas de famílias para outros espaços do bairro e da cidade. A chamada "regularização" dessa área foi acompanhada, entre outras coisas, do realinhamento, alargamento e abertura de ruas; realinhamento de cercas e muros; drenagem de áreas alagadiças e recuo e transporte de casas. Essas transformações foram viabilizadas por um financiamento realizado pelos gestores públicos junto ao governo federal: o Projeto CURA ${ }^{5}$. Estes projetos foram elaborados e postos em prática sem a consulta aos trabalhadores do Pouso Frio e sem efetivamente assumir compromissos reais com a melhoria das condições de vida desses sujeitos.

Essa forma de conceber a gestão das desigualdades sociais na cidade, que homogeneíza os espaços e territórios ao modo das classes dominantes, infelizmente, é prática ainda comum nos centros urbanos brasileiros. Essa "gestão científica" da cidade presume uma racionalidade extrínseca às desigualdades sociais urbanas que deveria nortear a condução não-política, "competente", "eficiente", das políticas públicas. Supostamente há uma forma "científica" - isto é, "neutra", talvez acima dos interesses particulares e dos conflitos sociais em geral - da gestão dos problemas da cidade e das desigualdades sociais nela existentes. Haveria critérios objetivos, "científicos", que

\footnotetext{
${ }^{4}$ Neste artigo a autora avalia os avanços institucionais no campo do direito à moradia, do direito à cidade, do fortalecimento jurídico da noção de função social da propriedade e do reconhecimento dos direitos de posse no Brasil, nas últimas décadas.

${ }^{5}$ O Projeto Cura (Comunidade Urbana para Recuperação Acelerada) foi criado pelo BNH (Banco Nacional de Habitação), no âmbito da política nacional de saneamento, oriundo do Plano Nacional de Saneamento (Planasa), instituído em 1970. Sobre o projeto, Bortolotti (2007, p. 137 apud SANDOVAL) argumenta que os investimentos retornavam por meio da cobrança de impostos e da contribuição de melhorias à população. Esse tipo de projeto era diferente de outras intervenções urbanas pela preocupação financeira e econômica, e não uma proposta de alcance social. Os bairros nos quais o Projeto CURA era aplicado não eram necessariamente os que possuíam infraestrutura precária, mas sim aqueles localizados em regiões estratégicas da cidade, com fluxo significativo e potencial de ascensão dentro do plano urbano, visando tanto ao benefício econômico/comercial da cidade, quanto àquitação do empréstimo realizado pelo BNH para o projeto (SANDOVAL, 2014).
} 
poderiam nortear as medidas da administração pública - no caso do Pouso Frio ganha relevância a atuação dos engenheiros civis ${ }^{6}$.

A ocupação desse território foi planejada pela Industrial Madeireira e Colonizadora Rio Paraná S/A - MARIPÁ, que adquiriu junto à companhia imobiliária inglesa "Maderas del Alto Paraná" uma gleba de terras, denominada Fazenda Britânia, em 1947. Essa negociação foi facilitada pela legislação que proibiu que estrangeiros fossem proprietários de terras em zonas fronteiriças no Brasil. A atividade inicial foi a extração de madeira, exportada para a Argentina e o Uruguai, mas os ramos de atividades da Maripá multiplicaram-se até a década de 1960. O plano de colonização fundamentou-se em pequenas propriedades, com média de 10 alqueires paulistas, com um quadro climático extremamente favorável para a exploração agrícola.

Geni Maria Donassolo (1994) ao tratar do processo que ela denomina “colonização agrícola”, promovida pela Industrial Madeireira Colonizadora Rio Paraná S/A (Maripá), busca evidenciar os modos como os dirigentes da Maripá tentaram resguardar a compra dos lotes apenas aos descendentes de italianos e de alemães vindos do Rio Grande do Sul e Santa Catarina (sujeitos que "monopolizam" a memória social produzida por diferentes gestões do poder público municipal). Os sujeitos vindos de outras regiões, como paulistas e paraguaios, por exemplo, encontravam, segundo a autora, muitas dificuldades para se estabelecer nesse território - o que não impediu sua presença.

A principal dificuldade dos dirigentes da Maripá na tentativa de controlar quais grupos sociais iriam se estabelecer na cidade que se formava parece ter sido o fato de que havia um grande território (que abrangia uma área de 2.001.745 metros quadrados à margem esquerda do Rio Toledo), que não lhe pertencia. $O$ Pouso Toledo (posteriormente chamado Pouso Frio, hoje correspondente à Grande Vila Pioneira ${ }^{7}$, que

\footnotetext{
${ }^{6}$ As práticas da administração pública remontam, no Brasil, ao século XIX. Sidney Chalhoub (2012) ao investigar este processo, aponta possiblidades interessantes na história social para discutir a cidade e os diversos projetos dominantes para a cidade, mas também para historiar os processos de reformas urbanas. A ideologia investigada por ele, construída na segunda metade do século XIX, permitiu (e ainda permite) aos governantes ocultar, ou ao menos dissimular o sentido classista de suas decisões políticas.

${ }^{7}$ A Região Administrativa da Grande Vila Pioneira foi criada pela Lei 26 de 07/07/1993, com as seguintes delimitações: toma como ponto de partida o cruzamento da Avenida Senador Atílio Fontana com a Rua dos Pioneiros. Segue por esta em direção Leste, até a Rua São Francisco Falso. Por esta, em direção ao Sul, até a divisa com o lote rural n4 do Perímetro "B" da Fazenda Britânia, por onde segue, em direção Leste, até a sanga Pinheirinho. Por esta até a sua confluência com o Arroio Toledo, pelo qual desce até a Avenida Senador Atílio Fontana. Segue por esta, em direção ao Sul, até o cruzamento com a Rua dos Pioneiros, ponto de partida da descrição (área de aproximadamente quatrocentos hectares). A Administração Regional passou a ser coordenada por um Administrador Regional (cargo em comissão) (TOLEDO, 1993). Não foi encontrado um mapa que especificasse essas delimitações.
} 
engloba os bairros Boa Esperança, Vila Paulista e Vila Pioneira), que durante muito tempo foi utilizado pela empresa Nunes Y Gibaja como uma parada para descanso de homens e animais, durante o transporte de erva-mate, passou a ser ocupado por pessoas vindas de diversos lugares e regiões do Paraná e do Brasil ${ }^{8}$. O mapa político atual da área urbana na cidade permite dimensionarmos a grande área do Pouso Frio/Vila Pioneiro em relação à cidade como um todo:

\section{Figura 1 - Mapa de Pouso Frio}

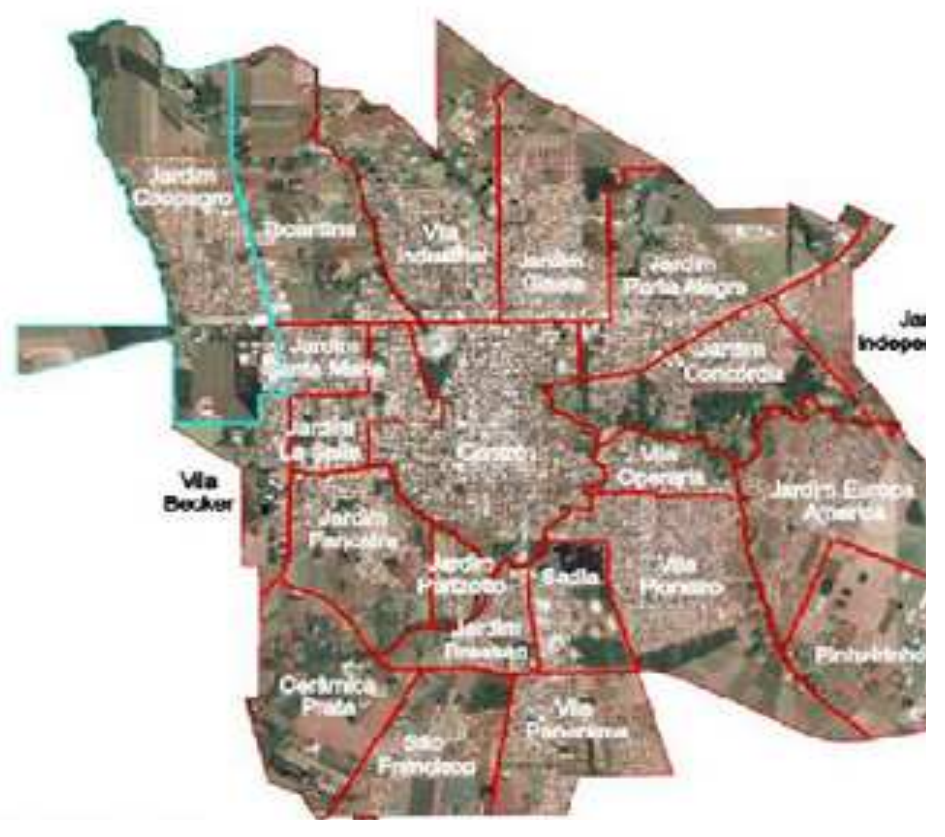

A antiga propriedade "Lopeî" (53.973 ha), composta por 5 áreas na região, foi registrada primeiramente pelo Estado do Paraná, firmada por João Cândido Ferreira (Vice Presidente do Estado), em 25 de agosto de 1905, em favor da empresa "Nunes y Gibaja". Mais tarde, por escritura pública de dissolução social dessa empresa, lavrada na cidade de Posadas, Provincia de Misiones, na República Argentina, em 14 de março de 1911, o imóvel foi dividido entre os sócios Pedro Nunes e Lázaro Gibaja. Quando

\footnotetext{
${ }^{8}$ Segundo Donassolo (1994, p. 40-41), em 1930, a empresa Nunes Y Gibaja, devido a dificuldades surgidas para exportar erva-mate, suspendeu suas atividades, deixando de usar este e os outros quatro pousos, além do imóvel chamado Lopeí (hoje interior de Cascavel, fazendo divisa com o município de Toledo). Estas cinco áreas eram numeradas de 1 a 5, partindo do Rio Paraná: Pouso Doze de Outubro (Porto), Arroio Grande, Guajuvira, Palmito e Toledo. A erva-mate semipronta era transportada no lombo de animais pela Picada Nunes e Gibaja desde a região de Cascavel, passando de pouso em pouso, até chegar ao Rio Paraná. Lá era embarcada e seguia para beneficiamento e comércio nas cidades argentinas.
} 
este último faleceu, em 31 de janeiro de 1924, sua parte no imóvel foi partilhada entre seus 4 filhos (Avelino Gibaja; Cesar Gibaja e Arrechea; Lázaro Gibaja Filho; Laura Gibaja Arrechea de Serra).

Em 4 de setembro de 1928, por escritura pública de "divisão de condomínio e permuta”, toda a propriedade Lopeí, incluindo a parte de Pedro Nunes, foi dividida novamente em duas partes iguais, cada qual com um único proprietário: Lázaro Gibaja Filho e Avelino Gibaja. Na mesma escritura os irmãos dividiram, em partes iguais, por metade, 5 frações de terra (cada uma com 200 hectares), denominadas de "pousos".

Mais tarde, por força de carta de adjudicação, conforme sentença proferida nos autos de execução do Juiz de Direito da Comarca de Foz do Iguaçu, com data de 23 de julho de 1932, Avelino Gibaja cedeu sua parte na propriedade (26.986 ha) para seu credor, Teodoro M. Soldatti (TOLEDO, 1963) ${ }^{9}$.

Entre 23 de julho de 1932 e 21 de maio de 1947 há uma lacuna nos arquivos verificados durante a pesquisa. Há certidões que indicam que em 21 de maio de 1947, Elvira Maria E. de Gibaja, Alcira H. Gibaja, Luiza J. Gibaja e Alcira Gibaja de Alonso (a primeira era viúva de Lázaro Gibaja Filho e as três últimas possivelmente eram as filhas do casal) registraram uma escritura de "Cessão de Ações e Direitos Hereditários" para David Wille Lupion, diretor comercial das Indústrias Lupion Limitada (PARANÁ, 1947) $)^{10}$.

O Pouso Toledo estava então dividido entre David W. Lupion e Teodoro Soldatti. Este último vendeu parte de sua área $\left(580.800 \mathrm{~m}^{2}\right)$ no Pouso Toledo para a Prefeitura Municipal de Toledo representada pelo Prefeito Municipal Avelino Campagnolo, no início do ano de 1965 (PARANÁ, 1965) ${ }^{11}$ e parte $\left(251.350 \mathrm{~m}^{2}\right.$ ) para Ivo Vanzella, agricultor na cidade de Cerro da Lola (PARANÁ, 1972) ${ }^{12}$. A Prefeitura Municipal de Toledo doou esta grande área em 1967, dois anos depois, para o Frigorífico Pioneiro S/A (PARANÁ, 1967) ${ }^{13}$.

\footnotetext{
${ }^{9}$ TOLEDO (Município). Certidão n ${ }^{\circ} 69 / 63$. Registro Integral de Títulos, Documentos e Outros Papéis. Cascavel, 28 de junho de 1963. Arquivo do Departamento de Cadastro da Prefeitura Municipal de Toledo.

${ }^{10}$ PARANÁ (Estado). Comarca de Foz do Iguaçu. Certidão. Menotti F. Cademartori. Oficial do Registro Civil e Títulos e Documentos. 21 de maio de 1947.

${ }^{11}$ PARANÁ (Estado). Comarca de Toledo. Registro de Imóveis. Talão n 43. Página 164. Haroldo L. Hamilton. Oficial Vitalício. 6 de fevereiro de 1965.

${ }^{12}$ PARANÁ (Estado). Comarca de Toledo. Registro de Imóveis. Talão nº 120 . Página 167. Haroldo L. Hamilton. Oficial Vitalício. 23 de agosto de 1972.

${ }^{13}$ PARANÁ (Estado). Comarca de Toledo. Registro de Imóveis. Talão nº5. Página 35. Haroldo L. Hamilton. Oficial Vitalício. 3 de agosto de 1967.
} 
Em algum momento Olivio Michelon adquiriu uma área $\left(20.088 \mathrm{~m}^{2}\right)$ no Pouso Frio e vendeu por Cr\$10.000,00 para a Prefeitura Municipal de Toledo em 11 de novembro de 1976 (TOLEDO, 1976) ${ }^{14}$. Lotario Antonio Bracht também adquiriu uma área $\left(28.000 \mathrm{~m}^{2}\right)$ no Pouso Frio, que vendeu, por $\mathrm{Cr} \$ 3.000 .000,00$ (três milhões de cruzeiros) para a Prefeitura Municipal de Toledo em 7 de janeiro de 1982 (TOLEDO, 1982) ${ }^{15}$. Da mesma maneira, Natalino Vendramin e Ivo Zeni também venderam para a Prefeitura Municipal, uma área de $46.400 \mathrm{~m}^{2}$, por Cr\$6.400.000,00 em outubro de 1982 (TOLEDO, 1982) ${ }^{16}$. Henrique Jorge Isernhagem também adquiriu uma propriedade de $24.200 \mathrm{~m}^{2}$ no Pouso Frio. Em 1982 doou à Prefeitura de Toledo (TOLEDO, 1982) ${ }^{17}$. No mesmo ano, Teodoro Soldatti, que aparentemente ainda era proprietário de algumas áreas no Pouso Frio (entre elas, três com $65.595 \mathrm{~m}^{2}, 90.533 \mathrm{~m}^{2}$ e $1.990 \mathrm{~m}^{2}$ ) doou as mesmas para a Prefeitura Municipal de Toledo (TOLEDO, 1982) ${ }^{18}$. Essas doações de terrenos indicadas nas Certidões e Escrituras Públicas pesquisadas podem ser questionadas, tendo em vista que esses documentos podem ocultar outros elementos desse processo. Entretanto, não há fontes que indiquem que esses proprietários efetivamente receberam algo em troca pelos terrenos "doados".

É perceptível a complexidade do processo de identificação dos sujeitos que possuíam escrituras na área do Pouso Frio: 2.001 .745 metros $^{2}$, com inúmeros proprietários, nem todos coniventes com a desapropriação, apesar de milhares de famílias viverem ali. Em 1987, uma publicação da Prefeitura Municipal ${ }^{19}$ informa que o número de habitantes do município beirava os 100 mil. Na mesma publicação, indica-se que havia 22 mil moradores do "outro lado do rio" ${ }^{20}$, o que corresponde a

\footnotetext{
${ }^{14}$ TOLEDO. Certidão. Registro de Imóveis. Toledo, 1 de novembro de 1976. Arquivo do Departamento de Cadastro da Prefeitura Municipal de Toledo.

${ }^{15}$ TOLEDO (Município). Escritura pública de compra e venda em que figuram como outorgantes vendedores "Lotario Antonio Bracht", e sua esposa, e de outro lado como outorgada compradora a Prefeitura Municipal de Toledo. Livro n ${ }^{\circ} 87$. Folha n $^{\circ} 081.7$ de janeiro de 1982.

${ }^{16}$ TOLEDO (Município). Escritura pública de compra e venda em que figuram como outorgantes vendedores "Natalino Vendramin", e outros, e de outro lado como outorgada compradora a Prefeitura Municipal de Toledo. Livro n 87. Folha n ${ }^{\circ} 083.7$ de janeiro de 1982.

${ }^{17}$ TOLEDO (Município). Escritura pública de doação em que figuram como outorgantes doadores "Henrique Jorge Isernhagem", e sua esposa, e como donatária a Prefeitura Municipal de Toledo. Livro ${ }^{\circ}{ }^{95}$. Folha ${ }^{\circ} 023.10$ de maio de 1982.

${ }^{18}$ TOLEDO (Município). Escritura pública de doação em que figuram como outorgantes doadores "Teodoro M. Soldatti”, e de outro lado como outorgada donatária a Prefeitura Municipal de Toledo. Livro ${ }^{\circ}{ }^{95}$. Folha ${ }^{\circ}$ 027. 11 de maio de 1982.

194 ANOS: participação e democracia. Toledo: Comunidade no poder. n. 03, fev. 1987. p. 12-44. Esta publicação faz um balanço das transformações urbanísticas realizadas na gestão "Toledo: Comunidade no Poder".

${ }^{20} \mathrm{O}$ texto menciona a Vila Brasil e a Vila Pioneira (Pouso Frio).
} 
aproximadamente um quarto da população do município. Muitos trabalhadores, à época da escrituração dos terrenos (final da década de 1970 e boa parte da década de 1980), já moravam no Pouso Frio há aproximadamente 30 anos.

Há registros de moradores no Pouso Frio desde $1948^{21}$. E se o centro da cidade e os outros bairros foram construídos com planejamento prévio, com quadras grandes, ruas largas, lotes retangulares e padronizados, as dinâmicas de construção do espaço no Pouso Frio foram outras. As casas foram construídas sem muita preocupação com as ruelas que poderiam servir de passagem. Essas pequenas ruelas, e muitas das ruas existentes até hoje (principalmente na Vila Boa Esperança), se orientam para diferentes direções, não sendo difícil, para um morador de outro bairro, não habituado, se perder. Muitas ruas permanecem estreitas, tortuosas, muitas vezes sem saída. As casas de madeira, em sua maioria, eram pequenas para as famílias numerosas. Além das habitações precárias, o Pouso Frio era desprovido de infraestrutura, sem serviços médicos adequados, sistema educacional que atendesse à demanda ou transporte público acessível. Numa publicação da Prefeitura Municipal de Toledo, esse processo é descrito da seguinte maneira:

No início, eram apenas alguns. Chegando, como sempre, em busca de uma oportunidade. E se instalavam num pedaço daquele chão do chamado Pouso Frio. Ninguém sabia de quem era aquele chão. Era esperar pra ver. Depois veio o primo, o irmão, o amigo, o conhecido... E foram se instalando. Os primeiros cedendo um tanto do tanto que tinham e os últimos se acomodando nos espaços ainda vazios, nem sempre com a concordância do vizinho. Era levantar o barraco durante a noite, de preferência com a porta para o lado oposto à do barraco mais próximo, e aguardar. Via de regra, depois de feito, não havia muito o que reclamar. A solução era ir se acomodando. E assim as "PROPRIEDADES" foram surgindo, primeiro às dezenas, depois às centenas. Os terrenos eram medidos com cordas ou fios de arames pelos interessados de ambas as partes, estabelecendo divisas que se modificavam constantemente de acordo com o ditado "quem pode mais chora menos". As áreas eram calculadas das mais variadas formas como, por exemplo, efetuando a soma das medidas de contorno, ou seja, o perímetro do lote. $\mathrm{O}$ resultado era expresso nos contratos de Compra e Venda como área de " $\mathrm{X}$ " metros quadrados.

Com o passar do tempo, as divisões e subdivisões das áreas foram se intensificando de maneira incontrolável, originando "terrenos" com áreas inferiores a 80,00 metros quadrados. Paralelamente, para agravar ainda mais a situação, a inexistência de um mapeamento da região impedia qualquer controle por parte do Poder Público, e a situação passou a se tornar insustentável, considerando-se então o grande número de pessoas envolvidas. Sem infraestrutura básica, formou-se a ocupação desordenada do solo, com

\footnotetext{
${ }^{21}$ Abel Batista de Freitas, nascido em 23 de janeiro de 1917, chegou a Toledo em 1948 e foi morar no chamado "Pouso Frio". Muito conhecido e requisitado como boiadeiro, domava juntas de bois para puxar carroças e para puxar toras de madeira. Seu nome foi atribuído a uma rua no Jardim Coopagro (COLOGNESE, 2011).
} 
milhares de pessoas em condições sub humanas de habitação. Estava caracterizado um drama social de grandes proporções. Grande parte dessas propriedades sem água, sem luz, sem acesso, verdadeiros depósitos de seres humanos nas mais deploráveis condições de higiene e sobrevivência. ERA PRECISO REVERTER ESSE QUADRO. (TOLEDO, 1988). ${ }^{22}$

Essa publicação da Prefeitura Municipal, apesar de responsabilizar exclusivamente os trabalhadores pelas suas precárias condições de moradia e de vida, cabendo supostamente ao poder público municipal, por iniciativa própria, "reverter esse quadro", indica alguns elementos que efetivamente caracterizaram o processo de ocupação do Pouso Frio. A possibilidade de instalar-se naquela área com donos desconhecidos e ausentes, associada à necessária busca de trabalho em tempos difíceis, bastava para uns indicarem aos outros, familiares e amigos, os benefícios da mudança. Planejar a organização do espaço nos parâmetros propostos pelos gestores públicos naquele momento não era prioridade. A urgência de instalar-se e a preocupação em não gerar conflitos com os moradores mais antigos era o mais importante.

A forma como o bairro foi se constituindo dificultou posteriormente a escrituração dos terrenos nos padrões regulamentados pela legislação municipal. Em um documento enviado ao Cartório do $1^{\circ}$ Ofício do Registro de Imóveis da Comarca de Toledo/PR, em julho de 1987, o remetente, João Carlos Poletto, ao referir-se ao Pouso Frio, escreve que

[...] existia ruas abertas e quadras e lotes totalmente ocupados, tornando-se impossível sua regularização, eis que existiam ruas com largura menor, lotes com áreas mínimas inferiores à legal, área de uso público menor do que a exigida por lei, dentre outras irregularidades, como lotes encravados (sem saída), becos sem saída, falta de infraestrutura, etc. (TOLEDO, 1987). ${ }^{23}$

Para além dessas peculiaridades, o remetente menciona ainda o processo judicial de expropriação de onde se expediu a carta de sentença, que serviu como título da propriedade, e solicita que não seja necessária a entrega de outros documentos para registro do imóvel ${ }^{24}$.

Certamente, a lógica de organização utilizada pelos trabalhadores para a construção de suas moradias era diferente da concepção de urbano dos gestores e

\footnotetext{
${ }^{22}$ TOLEDO (Município). Pouso Frio: Breve Roteiro. Toledo: Comunidade no Poder. Toledo, 35 anos. uma explosão de progresso. Fev. 1988.

${ }^{23}$ TOLEDO (Município). Ao Cartório do $1^{\circ}$ Ofício do Registro de Imóveis da Comarca de Toledo/PR. $1^{\circ}$ de julho de 1987.

${ }^{24}$ Certidão Vintenária; Certidão de Ônus Real; Certidão de Ações Reais; Certidões Negativas de Impostos Municipais, Estaduais e Federais.
} 
engenheiros. A ocupação do Pouso Frio atendeu às necessidades imediatas dos trabalhadores pobres que chegavam à cidade. O projeto de uma cidade "limpa", "saneada", "disciplinada", entre tantos outros, compõe o projeto de cidade das classes dominantes ${ }^{25}$.

O poder público municipal, por sua vez, ignorou esses sujeitos até o final da década de 1970, quando se fizeram ver e ouvir. Aparentemente, ao ignorar esse "universo de clandestinidade", os gestores públicos permitiram a existência de uma válvula de escape para as necessidades objetivas e concretas que a massa de trabalhadores urbanos, e a massa pobre, desempregada, recém-chegada do campo, tinha de habitação. Ermínia Maricato indica que esse posicionamento do Estado pode ser uma forma também de “[...] viabilizar o corte entre a provisão capitalista de habitações e a não capitalista, assegurando para a primeira os recursos disponíveis. É uma forma ainda, também, de viabilizar a reprodução barata, da força de trabalho.” (MARICATO, 1987, p. $31)$.

O número expressivo de trabalhadores que chegaram à cidade de Toledo nas décadas de 1950-70, predominantemente em busca de trabalho, não foi atendido satisfatoriamente por políticas públicas de habitação, saneamento ou educação. A ausência de provisão das necessidades materiais mais emergentes foi sanada, precariamente, pelos próprios trabalhadores.

Maria Madalena Gonçalves, 79 anos, veio de Catanduvas para Toledo, aproximadamente em 1966. As dificuldades financeiras e a avaliação de que não poderiam mais trabalhar no campo, motivou a mudança com seus 5 filhos para a cidade em que morava seu pai: "eu vim de mala e cuia, só com os filhos e a boca pra comer" (referência). A propriedade, se Maria Madalena recorda-se bem, tinha 10 alqueires: "Mas daí aquela época não tinha ajuda de maquinário nada, lá era tudo braçal né? Daí deixamos lá, depois vendemos lá". ${ }^{26}$ Apesar da propriedade não ser pequena, o acesso e o crédito aos maquinários agrícolas para o cultivo não era fácil. A família avaliou que desfazer-se da terra era a melhor alternativa.

O pai de Maria Madalena, Ernesto Ferreira de Almeida, trabalhava no frigorífico Pioneiro (posteriormente Frigobrás/Sadia) e a expectativa era que seu marido também

\footnotetext{
${ }^{25}$ Entre as práticas da administração pública, se evidenciou a aplicação de multas aos moradores que tivessem lixo em seus terrenos e a construção de banheiros no Pouso Frio.

${ }^{26}$ GONÇALVES, Maria Madalena. Entrevista realizada por Maria Cristina de Castro Pereira. Dia 20 de novembro de 2014. Duração: 47:27 min.
} 
conseguisse empregar-se ali - expectativa que se concretizou. Quando chegaram, alugaram dois cômodos de seu pai, no Pouso Frio, que serviu como moradia. Depois de 3 anos, conseguiram construir uma pequena casa. Seu pai possuía uma chácara que ocupou, que "aquela época era tempo que pegava assim, entrava e fazia posse de terra". O pai de Maria Madalena foi um dos trabalhadores que cercou e ocupou terras no Pouso Frio (aproximadamente meio alqueire). Segundo Maria Madalena, “[...] quem pôs o nome da Pioneira foi o pai. Ele escreveu numa tábua, com carvão, na esquina ali da Rua dos Pioneiros - mas não tinha a rua ainda. [...] ele escreveu numa tábua "aqui vai ser o loteamento, a Vila dos Pioneiros". E pegou! Só que não tem nada no nome dele aí." 27

Maria Madalena, ao afirmar que "não têm nada no nome dele aí", apesar de ser um dos primeiros moradores do Pouso Frio e quiçá da cidade, está reclamando, indiretamente, que a trajetória do pai foi obscurecida nas memórias públicas da cidade.

Diversas praças, ruas e monumentos na cidade fazem referência aos "pioneiros". Jiani F. Lângaro afirma que é hegemônico o entendimento de que a "colonização" e o tempo dos "pioneiros" são sinônimos de história local e regional, na condição de enredo obrigatório - quando não único - para se narrar o passado da cidade de Toledo (LANGARO, 2012, p. 16).

Segundo o autor, essas memórias do "pioneirismo" foram apropriadas por setores hegemônicos da sociedade, com o fim de demarcar espaços. Assim, "sob o argumento de valorizar os moradores considerados antigos no município, serviam como instrumento para construir e reafirmar as relações de poder ali existentes." (LANGARO, 2012, p. 17). A partir da década de 1980, essas iniciativas de produção de memórias intensificaram-se, justamente quando se intensificou a vinda de trabalhadores rurais para a cidade. O "bloco de poder" local buscava reafirmar sua hegemonia (LANGARO, 2012).

Nesse processo que resultou na hegemonização de determinadas memórias sobre a cidade, alguns sujeitos e grupos sociais escolheram certas versões do passado local para figurar como "História de Toledo". Dessa forma, alguns personagens - e entre eles não está o pai de Maria Madalena - ganharam visibilidade, enquanto outros foram relegados à obscuridade (LANGARO, 2012, p. 25). Estes últimos não foram esquecidos pelos familiares, amigos e vizinhos, que como Maria Madalena ainda reafirmam sua atuação na construção da cidade e reivindicam sua memória. Sobre o viver no Pouso

\footnotetext{
${ }^{27}$ GONÇALVES, Maria Madalena. Entrevista realizada por Maria Cristina de Castro Pereira. Dia 20 de novembro de 2014. Duração: 47: 27 min.
} 
Frio, informa que "não tinha luz, a água era de poço". Ao ser questionada sobre o acesso a esses serviços onde morava anteriormente, reconhece que também não havia: “Nem rádio! Fui ver rádio aqui! Não tinha nada!”. ${ }^{28}$

Aparentemente, Madalena e sua família, a princípio, não sentiram drásticas diferenças no local de moradia, afinal, a ausência de serviços públicos era sentida anteriormente. Mas, se nesse primeiro momento, determinados serviços públicos não eram avaliados pelos trabalhadores como necessidades e direitos, as dificuldades experimentadas ao tentar "usufruir" a cidade provocaram outras expectativas e anseios: passaram a entender esses serviços como melhorias em suas condições de vida. Sobre suas experiências naquele momento, Maria Madalena interpreta que

Foi difícil! Foi difícil, porque eu trabalhava lá na cidade. Ia três vezes por semana lavar roupa em duas casas pra voltar em hora de eles [os filhos] ir pra aula ainda. Naquela época não tinha condução nenhuma. E rancho naquela época, não dizia rancho, dizia compra, né? Nós trazia tudo nas costas. De lá do centro aqui. ${ }^{29}$

A ausência de transporte público dificultava o acesso de Madalena ao que ela caracterizou como a própria cidade e não seu centro. Refere-se ao espaço urbano como se estivesse fora dele. Os serviços públicos que atendiam uma parte da população urbana não chegavam aos trabalhadores que viviam no Pouso Frio. Trabalhar ou fazer compras tornava-se uma atividade difícil quando não podiam dispor de transporte público - a "condução".

Maria Madalena, além de trabalhar lavando roupas para famílias que viviam no centro da cidade, lavava roupas e fazia marmitas para trabalhadores do frigorífico Sadia:

[...] quando não tinha ainda a lavanderia na Sadia, eu lavava roupa pra turma da matança, tirando água do poço, com aqueles macacão que vinha que era um sangue! Menina do céu! Só eu sei o que eu passei! Hoje meus braços não aguentam! Tirando água de poço e lavando roupa de frigorífico! E mandava dez marmitas de almoço ainda. [...] que naquela época não tinha refeitório. ${ }^{30}$

Se a ausência de transporte público passou a ser uma dificuldade na vida dessa trabalhadora, a falta de água encanada também. O seu trabalho, de lavadeira, exigia que

\footnotetext{
${ }^{28}$ GONÇALVES, Maria Madalena. Entrevista realizada por Maria Cristina de Castro Pereira. Dia 20 de novembro de 2014. Duração: 47: 27 min.

${ }^{29}$ GONÇALVES, Maria Madalena. Entrevista realizada por Maria Cristina de Castro Pereira. Dia 20 de novembro de 2014. Duração: 47: 27 min.

${ }^{30}$ GONÇALVES, Maria Madalena. Entrevista realizada por Maria Cristina de Castro Pereira. Dia 20 de novembro de 2014. Duração: 47: 27 min.
} 
realizasse constantemente a tarefa de pegar água no poço, o que lhe causou danos físicos sentidos até hoje. Até mesmo a construção do poço foi um sacrifício: "Primeiro eu puxava água de lá de baixo! Dentro de uma carroça, aquelas carriolinha. Nós enchia as latas de, nem lembro mais de quê. Sei que nós enchia lá. Até fazer poço". ${ }^{31}$

Tendo em vista essa trajetória, ao falar sobre a posterior escrituração dos terrenos no Pouso Frio, que foi acompanhada por diversas transformações no bairro, Maria Madalena caracteriza positivamente esse processo:

\begin{abstract}
Quando abriram a $1^{\circ}$ de maio [antiga "Rua do Pouso", mais estreita], a nossa casa era em cima da rua. Daí a prefeitura mudou pra cima, pra passar a Rua $1^{\circ}$ de maio. [...] Vieram, o prefeito naquela época era o Duílio Genari, ele que ajudou nós, fez uma barraca lá, aí mudou nossa casa tudo. A prefeitura mudou, né? [...] Eu achei bom porque daí veio a rua, veio o asfalto, veio tudo, né? Aí foi melhorando. ${ }^{32}$
\end{abstract}

Maria Madalena atribui as transformações urbanas que presenciou à iniciativa do prefeito Duílio Genari e não às pressões exercidas por moradores do bairro. Talvez isso se deva à distância que manteve de organizações de moradores na época, que reivindicavam melhorias no Pouso Frio, como associações de moradores e amigos do bairro e enfrentou algumas dificuldades nesse processo, mesmo avaliando que valeu a pena. A casa de Maria Madalena ficava em cima de onde os engenheiros e arquitetos que planejavam as reformas urbanas da prefeitura municipal projetavam alargar uma rua. Para isso, Maria Madalena morou em uma barraca de lona por 3 meses enquanto os gestores públicos providenciavam o recuo de sua casa de madeira para depois do recuo concertarem os estragos ${ }^{33}$. Seus móveis ficaram na casa de amigos e vizinhos: "cada um acolheu um pouco das coisas, dos trens."

Como indenização da parte de seu terreno que virou rua, Maria Madalena ganhou outro terreno na Vila Boa Esperança. Algum tempo depois, após um acidente de carro sofrido por seu marido, precisou vender esse terreno para pagar as despesas do concerto do carro - contrariando os interesses da família, que era mantê-lo para um dos filhos. Venderam apenas devido a essa situação de emergência.

\footnotetext{
${ }^{31}$ GONÇALVES, Maria Madalena. Entrevista realizada por Maria Cristina de Castro Pereira. Dia 20 de novembro de 2014. Duração: 47: $27 \mathrm{~min}$.

${ }^{32}$ GONÇALVES, Maria Madalena. Entrevista realizada por Maria Cristina de Castro Pereira. Dia 20 de novembro de 2014. Duração: 47: 27 min.

${ }^{33}$ Num relatório datado de 9 de agosto de 1988, intitulado "Legalização do Pouso Frio: Situação Geral dos Serviços Realizados", consta que mais de 150 casas foram reconstruídas "para concretizar a legalização". Arquivo do Departamento de Cadastro da Prefeitura Municipal de Toledo.
} 
As experiências de Maria Madalena são representativas de um modo de vida compartilhado pelos trabalhadores no Pouso Frio. A vinda do campo, a busca por moradia e trabalho na cidade, utilizando de uma intricada rede de solidariedades estabelecida com familiares e amigos, as dificuldades cotidianas crescentes e a construção de novas perspectivas sobre o viver na cidade. Se inicialmente a energia elétrica, a água encanada, a coleta de lixo e transportes públicos não significavam uma ausência para os trabalhadores recém-chegados do campo, alguns anos na cidade e as dificuldades da vida urbana contribuíram para a construção de expectativas diversas. 


\section{REFERÊNCIAS}

\section{Fontes primárias}

4 ANOS: participação e democracia. Toledo: Comunidade no poder. n. 03, fev. 1987. p. $12-44$.

PARANÁ (Estado). Comarca de Foz do Iguaçu. Certidão. Menotti F. Cademartori. Oficial do Registro Civil e Títulos e Documentos. 21 de maio de 1947.

PARANÁ (Estado). Comarca de Toledo. Registro de Imóveis. Talão n ${ }^{\circ}$ 43. Página 164. Haroldo L. Hamilton. Oficial Vitalício. 6 de fevereiro de 1965.

PARANÁ (Estado). Comarca de Toledo. Registro de Imóveis. Talão n¹20. Página 167. Haroldo L. Hamilton. Oficial Vitalício. 23 de agosto de 1972.

PARANÁ (Estado). Comarca de Toledo. Registro de Imóveis. Talão nº5. Página 35. Haroldo L. Hamilton. Oficial Vitalício. 3 de agosto de 1967.

TOLEDO (Município). Certidão $n^{\circ} 69 / 63$. Registro Integral de Títulos, Documentos e Outros Papéis. Cascavel, 28 de junho de 1963. Arquivo do Departamento de Cadastro da Prefeitura Municipal de Toledo.

TOLEDO. Certidão. Registro de Imóveis. Toledo, 1 de novembro de 1976. Arquivo do Departamento de Cadastro da Prefeitura Municipal de Toledo.

TOLEDO (Município). Escritura pública de compra e venda em que figuram como outorgantes vendedores "Lotario Antonio Bracht", e sua esposa, e de outro lado como outorgada compradora a Prefeitura Municipal de Toledo. Livro ${ }^{\circ} 87$. Folha $\mathrm{n}^{\circ} 081.7$ de janeiro de 1982.

TOLEDO (Município). Escritura pública de doação em que figuram como outorgantes doadores "Teodoro M. Soldatti", e de outro lado como outorgada donatária a Prefeitura Municipal de Toledo. Livro $n^{\circ} 95$. Folha $n^{\circ} 027.11$ de maio de 1982.

TOLEDO (Município). Escritura pública de compra e venda em que figuram como outorgantes vendedores "Natalino Vendramin", e outros, e de outro lado como outorgada compradora a Prefeitura Municipal de Toledo. Livro ${ }^{\circ} 87$. Folha $n^{\circ} 083$. 7 de janeiro de 1982.

TOLEDO (Município). Escritura pública de doação em que figuram como outorgantes doadores "Henrique Jorge Isernhagem", e sua esposa, e como donatária a Prefeitura Municipal de Toledo. Livro $n^{\circ}$ 95. Folha $n^{\circ} 023.10$ de maio de 1982.

TOLEDO (Município). Ao Cartório do $1^{\circ}$ Ofício do Registro de Imóveis da Comarca de Toledo/PR. $1^{\circ}$ de julho de 1987. 
TOLEDO (Município). Pouso Frio: Breve Roteiro. Toledo: Comunidade no Poder. Toledo, 35 anos. Uma explosão de progresso. Fev. 1988.

TOLEDO (Município). Projeto de Lei $\mathbf{n}^{\circ} \mathbf{4 6} / \mathbf{1 9 9 3}$. Dispõe sobre a criação da Região Administrativa da Grande Vila Pioneiro e da respectiva Administração Regional. 24 de maio de 1993.

\section{Fontes secundárias}

CHAlHOUB, Sidney. Trabalho, lar e botequim. $3^{\mathrm{a}}$ Ed. Campinas: Ed. Unicamp, 2012.

CHIBA, Ariça; SOUZA, Ivanor Mann de. Práticas e representações na urbanização de Toledo - PR. 1994. 210 f. Monografia (Trabalho de Conclusão de Curso) Universidade Estadual do Oeste do Paraná, Departamento de História, Toledo, 1994.

COLOGNESE, Silvio Antônio (Org.). Ruas de Toledo: identidades que se cruzam. Cascavel: Edunioeste, 2011.

DONASSOLO, Geni Maria. O processo de seleção social no município de Toledo-PR. 1994. 82 f. Monografia (Trabalho de Conclusão de Curso) - Universidade Estadual do Oeste do Paraná, Departamento de História, Toledo, 1994.

LANGARO, Jiani Fernando. Quando o futuro é inscrito no passado: "Colonização" e "Pioneirismo" nas memórias públicas de Toledo-PR (1950-2010). 2012. 470 f. Tese (Doutorado em História) - Pontifícia Universidade Católica de São Paulo, Programa de Pós-graduação em História, São Paulo, 2012.

MARICATO, Ermínia. Política Habitacional no Regime Militar. Petrópolis: Editora Vozes, 1987.

ROLNIK, Raquel. História urbana: História na cidade? Cidade e História, v. 2, n. 1, p. 27-29, 1993. Disponível em: <http://unuhospedagem.com.br/revista/rbeur/index.php/ shcu/article/view/324/300>. Acesso em: 22 mar. 2015.

ROLNIK, Raquel. A construção de uma política fundiária e de planejamento urbano para o país - avanços e desafios. In: IPEA. Políticas sociais - acompanhamento e análise. 12. Fev. 2006. p.199-210.

ROLNIK, Raquel. Democracia no fio da navalha. Limites e possibilidades para a implementação de uma agenda de Reforma Urbana no Brasil. Estudos Urbanos e Regionais, Curitiba, v. 11, n. 2, p. 31-50, nov. 2009. Disponível em: <http://www.urbanismo.mppr.mp.br/arquivos/File/2194063PB.pdf>. Acesso em: 22 mar. 2015.

ROLNIK R. Moradia é mais que um objeto físico de quatro paredes. Emetropolis: Revista Eletrônica de Estudos Urbanos e Regionais, Rio de Janeiro, v. 2, n. 5, p. 3742, jun. 2011. Disponível em: http://emetropolis.net/edicao/n05. Acesso em: 26 fev. 2017. 
SADER, Eder. Quando novos personagens entraram em cena. Rio de Janeiro: Paz e Terra, 1988.

SANDOVAL, Francielle. Projeto CURA no Jornal Folha de Londrina: 1973-1977. Disponível em: <http://www.uel.br/eventos/sepech/arqtxt/PDF/franciellesandoval.pdf>. Acesso em: 14 nov. 2014.

SOUZA, João Carlos de. Na luta por habitação: a construção de novos valores. São Paulo: EDUC, 1995.

THOMPSON, Edward Palmer. A miséria da teoria ou um planetário de erros: uma crítica ao pensamento de Althusser. Rio de Janeiro: Zahar Editores, 1981. 